\title{
ASPERGILLUS TERREUS KMBF1501 A POTENTIAL PIGMENT PRODUCER UNDER SUBMERGED FERMENTATION
}

\author{
P. AKILANDESWARI, B. V. PRADEEP \\ Department of Microbiology, Karpagam University, (Karpagam Academy of Higher Education), Coimbatore 641021, Tamil Nadu, India \\ Email: bvpradeepku@gmail.com
}

Received: 14 Nov 2016 Revised and Accepted: 14 Feb 2017

\section{ABSTRACT}

Objective: The present study was aimed to identify the fungal isolate from soil and to understand the different optimized parameters better to facilitate the pigment production that has high yield and stability.

Methods: Aspergillus sp. was isolated from Western Ghats soil by the conventional serial dilution technique and assessed as a potential pigment producer. Different broth medium such as potato dextrose broth (PDB), czapek-dox broth (CDB), malt extract broth (MEB), rose bengal broth (RBB), sabouraud dextrose broth (SDB), yeast malt extract broth (YEMB), pH (3-9), temperature (24, 27, 30, 33, 37 and 40 ${ }^{\circ} \mathrm{C}$ ), carbon (lactose,glucose,sucrose, maltose, galactose and fructose) and nitrogen source (peptone, yeast extract, urea and inorganic nitrogen sources like potassium nitrate, ammonium chloride and sodium nitrate), mineral salts such as sodium dihydrogen phosphate ( $\left.\mathrm{Na}_{2} \mathrm{H}_{2} \mathrm{Po}_{4}\right)$, magnesium sulphate $\left(\mathrm{Mg}_{2} \mathrm{So}_{4}\right)$, calcium chloride $\left(\mathrm{CaCl}_{2}\right)$, copper sulphate $\left(\mathrm{Cu}_{2} \mathrm{So}_{4}\right)$, potassium dihydrogen phosphate $\left(\mathrm{KH}_{2} \mathrm{Po}_{4}\right)$ and manganese sulphate $\left(\mathrm{Mn}_{2} \mathrm{So}_{4}\right)$ and inoculum age (2-7 d) of the medium related to high pigment production were analysed.

Results: Aspergillus terreus KMBF1501 was identified by ribosomal DNA sequencing showing 99\% similarity with other Aspergillus terreus and the accession number (KX113516) was assigned. The optimum culture conditions for pigment production by Aspergillus terreus KMBF1501 was achieved at $\mathrm{pH} 5(0.563 \pm 0.012 \mathrm{~nm})$, temperature of $27{ }^{\circ} \mathrm{C}(0.382 \pm 0.001 \mathrm{~nm})$ with glucose $(0.501 \pm 0.002 \mathrm{~nm})$ as carbon source, peptone $(2.147 \pm 0.004 \mathrm{~nm})$ as nitrogen source, $\mathrm{Mg}_{2} \mathrm{SO}_{4}(0.401 \pm 0.001 \mathrm{~nm})$ as mineral salt and $4 \mathrm{~d}(0.324 \pm 0.001 \mathrm{~nm})$ of inoculum age in PDB $(0.761 \pm 0.006 \mathrm{~nm})$.

Conclusion: Aspergillus terreus KMBF1501 produced maximum pigment when cultured in modified PDB than in common PDB medium. The high concentration of the pigment can be used for various industrial purposes.

Keywords: Pigment, Aspergillus terreus, Submerged fermentation, Western Ghats, Industrial application

(C) 2017 The Authors. Published by Innovare Academic Sciences Pvt Ltd. This is an open access article under the CC BY license (http://creativecommons.org/licenses/by/4. 0/) DOI: http://dx.doi.org/10.22159/ijpps.2017v9i4.16176

\section{INTRODUCTION}

Diverse group of fungi are known to harbor in soil and the Western Ghats are considered to be the hot spot location for the biodiversity including microorganisms [1]. Among the microorganisms in the soil, the fungi are metabolically active to produce many substances including pigments [2]. Fungi produce an inspiring array of secondary metabolites [3] and the benefits range like the beneficial bioactive compounds such as antibiotics, anticancer, antimicrobial and antioxidants. The discoveries of these secondary metabolites have more interest for the pharmaceutical and agrochemical industries [4]. The regulation of several secondary metabolites are influenced by various environmental stimuli such as carbon and nitrogen sources, temperature, light, $\mathrm{pH}$, amino acids, reactive oxygen species and iron availability. The effects of the environmental factors such as physical and chemical factors on the growth of fungi are generally less definite and controlled than the effect of the secondary metabolite production. Hence, it is reported that the fungal growth depends on the composition of the growth medium, $\mathrm{pH}$, temperature, light and the surrounding atmospheric gas mixture [5]. Pigments derived from the natural sources are increased due to the disquiet of the potential toxicity of several synthetic dyes [6] which are used extensively in the food, cosmetics and pharmaceutical industries [7]. Mostly the pigment production in submerged culture is affected by several environmental factors. It is mostly affected by the nitrogen source and $\mathrm{pH}$ of the medium [8]. The pigments commonly produced by the fungi belong to the aromatic polyketide groups such as melanins, quinines [9], flavins, ankaflavin, anthraquinone and naphthoquinone [10]. It is known that the fungi isolated from the soil the produce pigments which are used for various industrial applications. The uses of fungal pigments are gaining accessibility in textile dyeing, food colorant, antimicrobial, and anticancer activities. Incidentally, the fungal pigments are natural without creating undesirable effects when they enter the environment. Considering the toxic effects of the synthetic dyes, the natural dyes are eco-friendly and easily degradable since they cause no detrimental effects [11].

Aspergillus sp. are filamentous fungus belongs to Trichocomaceae family, changes in the metabolism known as secondary metabolism when the organism enters a period of slower growth and the morphological alteration under the conditions of the nutrient limitation such as deficiency of the assimilated carbon, nitrogen or phosphorus sources [12]. Aspergillus sp. is known to produce metabolites which are fast growing and are easily obtained from various substrates. Moreover, there are many studies that reveal about the natural chemistry of Aspergillus metabolites, in particular, Aspergillus terreus are abundant producers of secondary metabolites. The pigment anthraquinone from Aspergillus strain is reported to have a commercial importance [13]. In general, the pigments produced by Aspergillus sp. have antibacterial activity, antifungal activity [14] and were also used in the textile dyeing [15]. Moreover, the most active extracts obtained from Aspergillus sp. are subjected to the phytotoxic and herbicidal activities [16]. The compounds produced by Aspergillus terreus include aspulvinone, an active natural product capable of inhibiting influenza An H1N1 virus $[12,17]$ and asterriquinone, a metabolite of Aspergillus terreus found to have antitumor activity [18]. In this work, the fungi Aspergillus terreus KMBF1501 was isolated and screened from the soil samples to provide the information about the optimised fermentation conditions in order to know its ability to produce pigments with more yield and stability.

\section{MATERIALS AND METHODS}

Isolation, purification and identification of pigment-producing fungi

Soil samples were collected from the surface $(1-3 \mathrm{~cm}$ depth) of the interior areas of Idukki district, biodiversity in the Western Ghats 
Kerala, India. The collected samples were packed in the sterile polyethene bags and carefully transported to the laboratory. The isolation of the fungi from soil was done by transferring $1 \mathrm{~g}$ of soil to a tube containing $9 \mathrm{ml}$ of distilled water from $10^{-2}$ to $10^{-5} \mathrm{~g} / \mathrm{ml} .0 .1 \mathrm{ml}$ of soil sample was inoculated in PDA and performed in triplicates amended with chloramphenicol (50 mg) (to control bacterial growth). The plates were incubated at room temperature $\left(25 \pm 2{ }^{\circ} \mathrm{C}\right)$ for five days. Fungal pigments which were attractive and bright colored were transferred to fresh PDA medium and confirmed for its color production. The pigment producing fungal isolates were purified by single hyphal tip method using PDA medium. Colonies that grew in the incubation period of $5 \mathrm{~d}$ in room temperature $(25 \pm 2$ ${ }^{\circ} \mathrm{C}$ ) were observed for fungal colonies producing pigments. The purified colonies were transferred to PDA slants and stored for the further study. The fungi which released pigment in the flask containing PDB medium was visualized after $14 \mathrm{~d}$ of fermentation and identified. The morphological features of the selected fungi were identified macroscopically and microscopically using Nikon Eclipse E200 series, Japan at the magnification of 40X. This is done with mycelia of the selected fungal isolate using lactophenol cotton blue test [19]. Further, the species level of the selected fungi was confirmed and identified at the Mycology and Plant Pathology Laboratory, Agharkar Research Institute, Pune.

\section{Optimization of the fermentation parameters on pigment production by Aspergillus terreus KMBF1501}

On the basis of high pigment production, the different broth medium and parameters which influence the pigment production like $\mathrm{pH}$, temperature, carbon and nitrogen source, mineral salts and inoculum age were investigated.

\section{Pigment production in various broth medium}

Different broth media such as potato dextrose broth (PDB), czapekdox broth (CDB), malt extract broth (MEB), rose bengal broth (RBB), sabouraud dextrose broth (SDB), yeast malt extract broth (YEMB) (Hi media) were used for the growth and pigment production of the selected fungal culture Aspergillus terreus KMBF1501. Sterilized broth medium was dispensed in each flask and inoculated with the fungal mycelial disc, for seven days incubation time at $25 \pm 2{ }^{\circ} \mathrm{C}$. The growth of the fungal colony and pigment production in the different broth medium were visually observed and examined [20]. The medium which produced maximum pigment production was used for the further study.

\section{Cultivation in submerged fermentation}

The optimization studies of various parameters were carried out to examine the fungal growth and pigment production. With slight modification, the culture medium was composed with different carbon and nitrogen source $(2 \% \mathrm{w} / \mathrm{v})$, mineral salts $(2 \% \mathrm{w} / \mathrm{v}), \mathrm{pH}$, temperature and inoculum age. Temperature $(24,27,30,33,37$ and $\left.40{ }^{\circ} \mathrm{C}\right), \mathrm{pH}(3-9)$, inoculum age (2-7 d) and the carbon sources (lactose, glucose, sucrose, maltose, galactose and fructose) were used. Nitrogen sources were studied by using different organic nitrogen sources including peptone, yeast extract, urea and inorganic nitrogen sources like potassium nitrate, ammonium chloride and sodium nitrate. Different mineral salts such as sodium dihydrogen phosphate $\left(\mathrm{NaH}_{2} \mathrm{Po}_{4}\right)$, magnesium sulphate $\left(\mathrm{Mg}_{2} \mathrm{So}_{4}\right)$, calcium chloride $\left(\mathrm{CaCl}_{2}\right)$, copper sulphate $\left(\mathrm{Cu}_{2} \mathrm{So}_{4}\right)$, potassium dihydrogen phosphate $\left(\mathrm{K}_{2} \mathrm{HPo}_{4}\right)$ and manganese sulphate $\left(\mathrm{Mn}_{2} \mathrm{So}_{4}\right)$ were investigated. The experiments were performed in an Erlenmeyer flask containing sterilized medium with the components, after inoculation they were maintained in the darkness for $14 \mathrm{~d}$ at the room temperature $(25 \pm 2$ ${ }^{\circ} \mathrm{C}$ ) in a static condition [21].

\section{Analysis of dry cell weight and extracellular pigment}

After the fermentation period, the samples were collected aseptically, centrifuged and filtered through no. 1 Whatman filter paper. The mycelial mat was washed twice with distilled water, dried at $50{ }^{\circ} \mathrm{C}$ for $48 \mathrm{~h}$ and the resulting biomass was weighed [22]. The extracellular yellow pigment production was estimated by the spectrophotometric method at $500 \mathrm{~nm}$. The uninoculated medium was used as a blank.

\section{RESULTS}

\section{Isolation and identification of Aspergillus terreus KMBF1501}

Soil samples collected from the Western Ghats ecosystem of Idukki district, Kerala were focused for the enumeration of total fungal colonies by the serial dilution technique plated on PDA medium. The isolated colonies were subjected for the pigment production and following to it screening among the soil samples collected, Aspergillus sp. showed the maximum yield by producing a yellow color pigment that had the high diffusing ability in both the solid and liquid medium (fig. 1a andb) respectively. The morphological characters of the culture demonstrated was sand brown in color with a yellow reverse and the microscopic observation (fig. 1c) showed vegetative hyphae, conidial heads globose to loosely radiate, vesicles globose to subglobose, sterigmata one to two series, conidia cylindrical with conidiphores. The molecular identification of the fungal isolate was confirmed by the ribosomal DNA sequencing at the Mycology and Plant Pathology Laboratory, Agharkar Research Institute, Pune. Based on it, the screened Aspergillus sp. KMBF1501 was confirmed as Aspergillus terreus showing $99 \%$ similarity with Aspergillus terreus (table 1). After submitting the sequence in NCBI, (GenBank Accession no. KX113516) the phylogenetic tree of Aspergillus terreus KMBF1501 was constructed in comparison with other Aspergillus terreus (fig. 2).

Table 1: Sequences producing significant alignments

\begin{tabular}{|c|c|c|c|c|c|c|}
\hline Description & $\begin{array}{l}\text { Max } \\
\text { score }\end{array}$ & $\begin{array}{l}\text { Total } \\
\text { score }\end{array}$ & $\begin{array}{l}\text { Query } \\
\text { cover }\end{array}$ & $\begin{array}{l}\text { E } \\
\text { value }\end{array}$ & $\begin{array}{l}\text { Max } \\
\text { identity }\end{array}$ & $\begin{array}{l}\text { Accession } \\
\text { no. }\end{array}$ \\
\hline $\begin{array}{l}\text { Aspergillus terreus strain 1z11 18S ribosomal RNA gene, partial } \\
\text { sequence }\end{array}$ & 1122 & 1122 & $95 \%$ & 0.0 & $99 \%$ & KT803070.1 \\
\hline Aspergillus sp. BAB-3258 18S ribosomal RNA gene, partial sequence & 1177 & 1177 & $100 \%$ & 0.0 & $99 \%$ & KU504311.1 \\
\hline Aspergillus sp. BAB-3312 18S ribosomal RNA gene, partial sequence & 1170 & 1170 & $99 \%$ & 0.0 & $99 \%$ & KU504316.1 \\
\hline Aspergillus terreus isolate 1 18S ribosomal RNA gene, partial sequence & 1114 & 1114 & $94 \%$ & 0.0 & $99 \%$ & KT360948.1 \\
\hline $\begin{array}{l}\text { Aspergillus terreus isolate } \mathrm{H} 1518 \mathrm{~S} \text { ribosomal RNA gene, partial } \\
\text { sequence }\end{array}$ & 1120 & 1120 & $95 \%$ & 0.0 & $99 \%$ & AY939788.1 \\
\hline Aspergillus terreus isolate A8 $18 \mathrm{~S}$ ribosomal RNA gene, partial sequence & 1118 & 1118 & $95 \%$ & 0.0 & $99 \%$ & JN129182.1 \\
\hline $\begin{array}{l}\text { Aspergillus terreus strain LCF17 18S ribosomal RNA gene, partial } \\
\text { sequence }\end{array}$ & 1116 & 1116 & $100 \%$ & 0.0 & $99 \%$ & FJ867934.1 \\
\hline $\begin{array}{l}\text { Aspergillus terreus strain AML02 18S ribosomal RNA gene, partial } \\
\text { sequence }\end{array}$ & 1146 & 1146 & $97 \%$ & 0.0 & $99 \%$ & KC354516.1 \\
\hline Aspergillus terreus $18 \mathrm{~S}$ ribosomal RNA gene, partial sequence & 1171 & 1171 & $100 \%$ & 0.0 & $99 \%$ & KM491895.1 \\
\hline
\end{tabular}



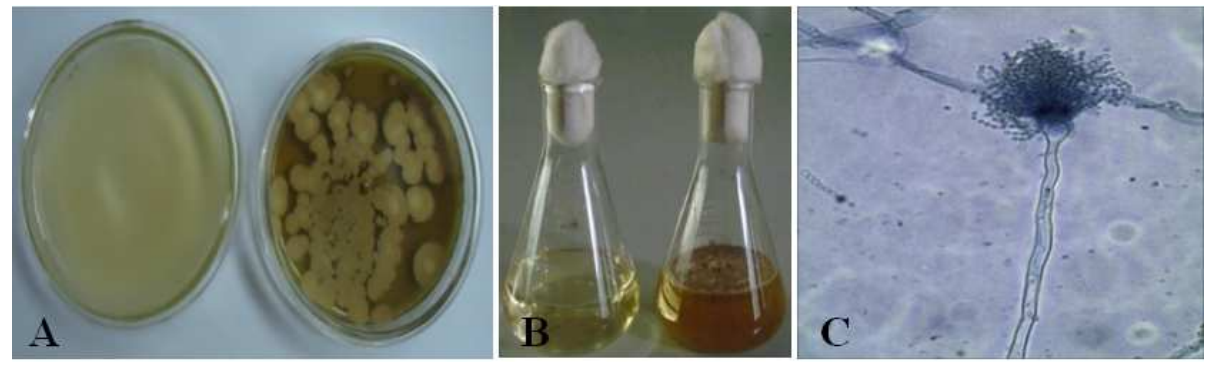

Fig. 1: (a) Aspergillus terreus KMBF1501 grown on potato dextrose agar (b) Pigment production on potato dextrose broth (c) Microscopically identified conidial head of Aspergillus terreus KMBF1501

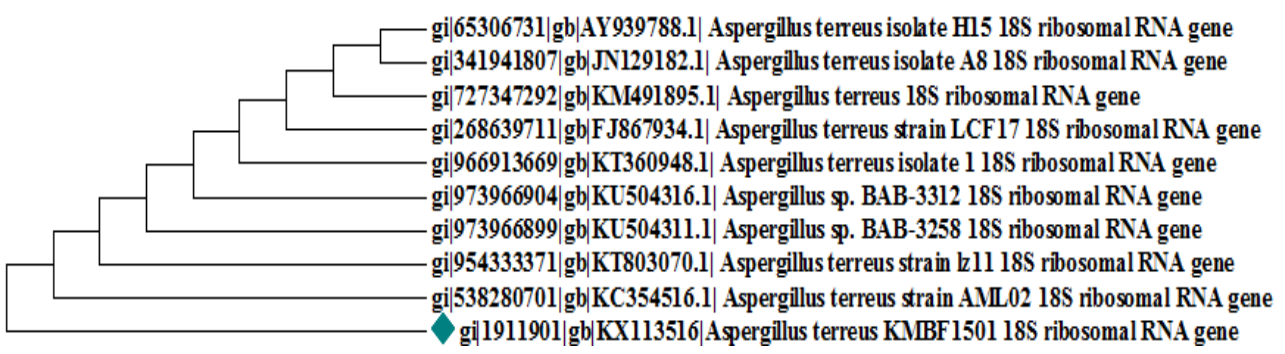

Fig. 2: Phylogenetic tree of Aspergillus sp

Optimization of different parameters on biomass and pigment production cultivated in submerged fermentation

Pigment production in the various broth medium

Various broth media (PDA, CDB, MEB, RBB, SDB, YMEB) were used to study their influence on the biomass and pigment production of the selected Aspergillus sp. measured at $500 \mathrm{~nm}$ aborbance. Among the broth media used, PDB, gave the best results for the biomass and pigment production of Aspergillus terreus KMBF1501 (fig. 3).

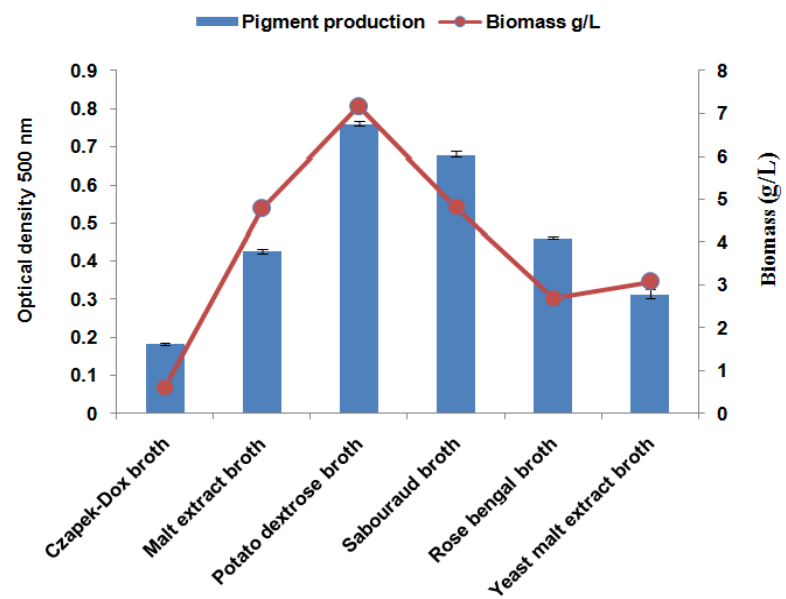

Fig. 3: Influence on six liquid medium for pigment production by Aspergillus terreus $\mathrm{KMBF1501;} \mathrm{n}=6$, mean \pm SD $(0.761 \pm 0.006 \mathrm{~nm})$

\section{Effect of medium pH and temperature}

To study the pigment production, the selected fungi were grown in the PDB medium at varying $\mathrm{pH}(3,4,5,6,7,8,9)$ and temperature $\left(24,27,30,33,37,40{ }^{\circ} \mathrm{C}\right)$. A maximum pigment production and high biomass concentration were observed at $\mathrm{pH} 5$ (fig. 4) and the incubation temperature of $27{ }^{\circ} \mathrm{C}$ was measured by the absorbance for the extracellular pigments (fig. 5). In the case of $\mathrm{pH} \mathrm{3,4,8,9}$ pigment production was very less. Generally, fungi prefer acidic $\mathrm{pH}$ for good growth and activity. High temperature reduced the pigment production and biomass yield.

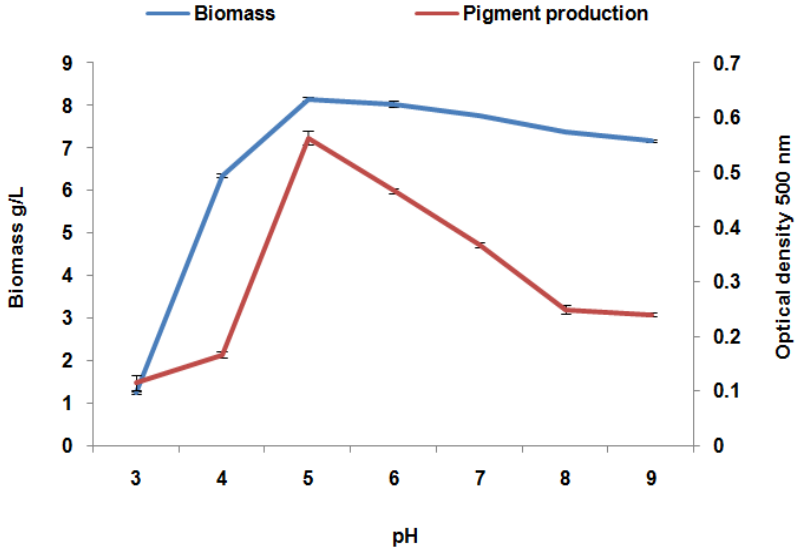

Fig. 4: Effect of $\mathrm{pH}$ on biomass and pigment production of Aspergillus terreus KMBF1501; $\mathrm{n}=6$, mean \pm SD $(0.563 \pm 0.012 \mathrm{~nm})$



Fig. 5: Effect of temperature $\left({ }^{\circ} \mathrm{C}\right)$ on biomass and pigment production of Aspergillus terreus KMBF1501; $n=6$, mean \pm SD $(0.382 \pm 0.001 \mathrm{~nm})$ 


\section{Effect of carbon and nitrogen source}

The carbon sources (lactose, glucose, sucrose, maltose, galactose and fructose) in the culture medium for the biomass production and pigment production in $2 \% \mathrm{w} / \mathrm{v}$ concentration was used in the study. Among the carbon sources used, the maximum absorbance at 500 $\mathrm{nm}$ was achieved when glucose was used (fig. 6). Different organic nitrogen sources such as peptone, yeast extract and inorganic nitrogen sources such as urea, potassium nitrate, sodium nitrate and ammonium chloride were used for the biomass and pigment production. Among the organic nitrogen sources, peptone gave the highest yield of pigment production and mycelial growth. By using the inorganic nitrogen sources, sodium nitrate gave a total mycelium growth as well as pigment production (fig. 7). In general, all the nitrogen sources support the pigment production. Among these, organic nitrogen sources were found to be better than inorganic nitrogen sources for increased pigment production.

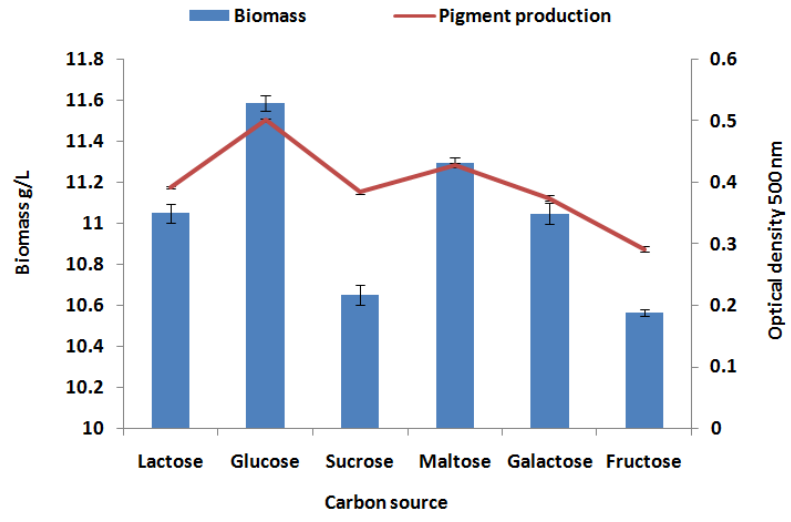

Fig. 6: Effect of carbon source on biomass and pigment production of Aspergillus terreus KMBF1501; $\mathrm{n}=6$, mean $\pm \mathrm{SD}$ $(0.501 \pm 0.002 \mathrm{~nm})$

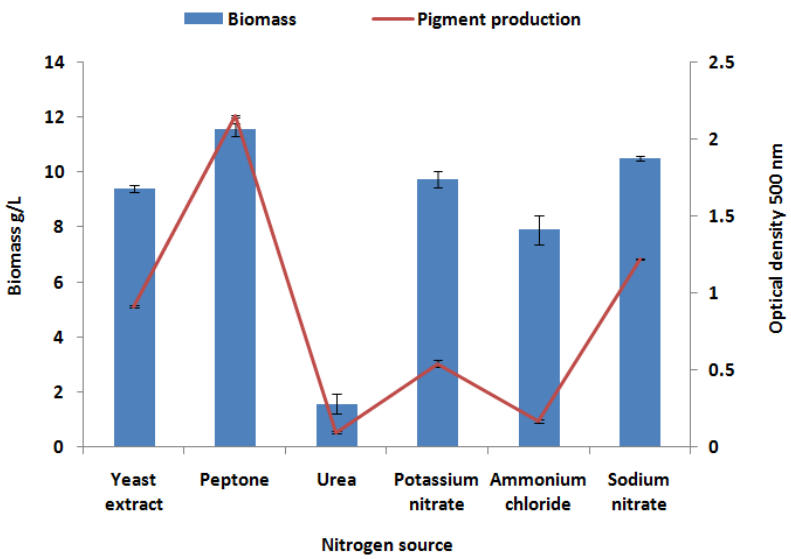

Fig. 7: Effect of nitrogen source on biomass and pigment production of Aspergillus terreus KMBF1501; $n=6$, mean $\pm S D$ $(2.147 \pm 0.004 \mathrm{~nm})$

\section{Effect of mineral salts and inoculum age}

The influence of mineral salts such as $\mathrm{NaH}_{2} \mathrm{Po}_{4}, \mathrm{Mg}_{2} \mathrm{SO}_{4}, \mathrm{CaCl}_{2}$, $\mathrm{CuSO}_{4}$, $\mathrm{KH}_{2} \mathrm{Po}_{4}$ and $\mathrm{MnSO}_{4}$ on biomass and pigment production was studied. Among the mineral salts used, the maximum absorbance at $500 \mathrm{~nm}$ was attained when $\mathrm{Mg}_{2} \mathrm{So}_{4}$ was used in the fermentation medium, whereas minimum pigment production and mycelial growth were observed in $\mathrm{CuSO}_{4}$ (fig. 8). Different inoculum age (2-7) of Aspergillus terreus KMBF1501grown in the medium showed maximal pigment and biomass production in the inoculum age of 4 that allowed the greater absorbance at the analyzed wavelength $500 \mathrm{~nm}$. In addition, with an increase in the inoculum age, there was a slight decrease in the biomass and pigment production and the least amount of pigment production was observed in the second day of the inoculum age (fig. 9).

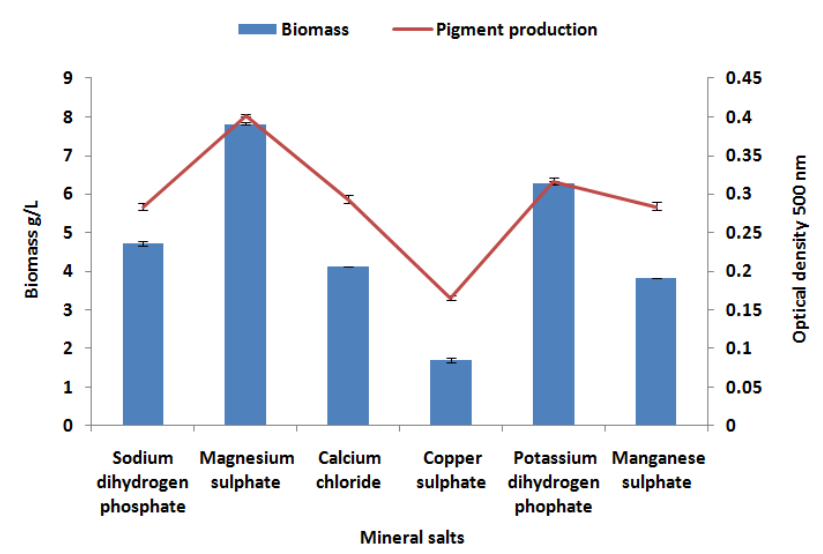

Fig. 8: Effect of mineral salts on biomass and pigment production of Aspergillus terreus KMBF1501; $\mathrm{n}=6$, mean \pm SD $(0.401 \pm 0.001 \mathrm{~nm})$

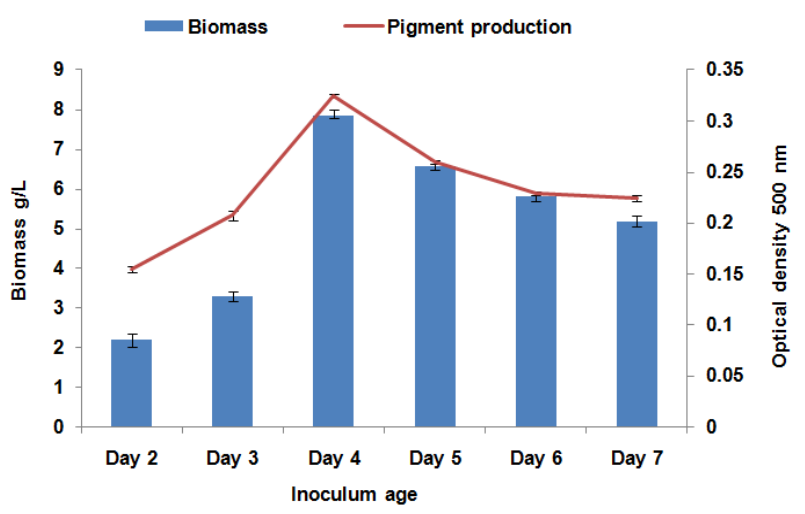

Fig. 9: Effect of inoculum age on biomass and pigment production of Aspergillus terreus $\mathrm{KMBF} 1501$; $\mathrm{n}=6$, mean $\pm \mathrm{SD}$ $(0.324 \pm 0.001 \mathrm{~nm})$

\section{DISCUSSION}

The present study was carried out to identify the fungal species producing pigments and their various optimal growth conditions. The soil samples were collected from the Western Ghats ecosystem of Kerala. The reason of selecting different soil samples was to investigate the biodiversity of the pigment-producing fungi. The number of pigment-producing fungi are considered to be high in the forest soils compared to other sources. Even if many species of fungi are capable of producing pigments in nature, screening was necessary to recognize the potent pigment producers. Some of the fungal isolates produced pigments under the specific growth conditions, but Aspergillus terreus KMBF1501 was found to produce high quantity of pigment which excreted intense yellow color. Celestino et al. (2014) [23] investigated that Aspergillus calidoustus 4BV13 sp. from the Amazon soil synthesised intensively coloured pigment which had the potential for a new source of natural dye. Filamentous fungi isolated from the Western Ghats ecosystem which produced a water soluble pigment that was used as an alternate for the leather dyeing as a natural dye. Moreover, that fungal pigment in dyeing process was found to enhance the availability of new possibility for the eco-friendly dyeing process and possess enormous efficiency as medicinally important products $[24,25]$.

In general, there are two forms of growth, the filamentous form and the pelleted form, mostly found in the fungal fermentation, the 
pelleted form is less viscous than the filamentous form [26]. Even though the fungal morphology is influenced by a variety of factors such as medium composition, agitation intensity and oxygen intensity, still it is difficult to relate the broth rheology to every aspects of the microbial morphology [27]. As the growth of the microorganism is influenced by various factors, $\mathrm{pH}$ of the culture medium and temperature of the incubation plays a significant role, as well as each microorganism, has a specific $\mathrm{pH}$ tolerance range for the growth and pigment production [28]. From the results, it was observed that the temperature $\left(27^{\circ} \mathrm{C}\right)$ and $\mathrm{pH}(5)$ appeared to be optimum for the growth and pigment production of Aspergillus terreus KMBF1501. The $\mathrm{pH}$ of the medium varies for both the mycelial growth and pigment production. The optimum $\mathrm{pH}$ and temperature of the fungal strain were $6.0,25 \pm 2{ }^{\circ} \mathrm{C}$ observed for growth and secondary metabolite production. Hence at the alkaline range, the growth and pigment production have been reduced indicating that the increase in the $\mathrm{pH}$ might result in a decrease of the pigment production and extraction rate [29,30]. Dufosse et al. (2005) [10] reported that the $\mathrm{pH}$ (5.6-6.2) was in the optimum culture condition to perform the fungal synthesis and generally, fungi prefer acidic pH for good growth and activity. Geweely (2011) [31] investigated that Aspergillus nidulans showed a positive effect on high biomass, intracellular and extracellular pigments when influenced at $\mathrm{pH} 7$ and temperature of $30^{\circ} \mathrm{C}$.

The results indicate that the glucose and peptone gave better biomass and pigment yield under submerged fermentation. Likewise, Aspergillus nidulans showed higher pigment production when peptone was used as the nitrogen source. Whereas for the carbon source, fructose was relatively favorable for the growth, but the pigment production was found to be low. In the case of carbon and nitrogen source, the mycelial growth and biosynthesis of many secondary metabolites were obtained when glucose was used as a carbon source [32], peptone and yeast extract as a suitable organic nitrogen source for the mycelial growth and pigment production [23]. Goudar et al. (1999) [27] reported that the carbon sources such as sucrose and glucose influenced the growth, while maltose influenced high pigment production in fungi.

Moreover, once this carbon source was completely utilized the biomass concentration stabilize indicating the onset of endogenous respiration. The literature describes that the nitrogen sources used by the fungus were influenced for the regulation of the several secondary metabolite gene clusters [5]. Juzlova et al. (1996) [33] reported that the pigment production is possible in submerged cultures by utilizing nitrogen sources. Sodium nitrate is known to support the sporulation, but the limited growth and gave an intermediate yield of the pigment production, while ammonium chloride enhanced the repression of the conidiation and the sexual cycle gives the best pigment yield. In addition, peptone gave better growth and pigment amounts when compared to the sodium nitrate and ammonium chloride [8]. Also, monosodium glutamate was the most favourable nitrogen source for the formation of the red pigments in MOPS-buffered (3-(N-morpholino) propane sulfonic acid) culture [34].

Many reports have suggested that the presence of metal ions such as zinc, iron and copper influence the fungal growth and metabolic synthesis, including a regulatory effect at the cellular and molecular levels. Moreover, this mainly depends upon the concentration of the metal ions and also the ligands in the substrate [35]. Medentsev and Akimenko (1998) [36] suggested the mineral salts $\mathrm{Mg}^{2+}, \mathrm{Fe}^{2+}$ and $\mathrm{Zn}^{2+}$ played an important role in the increase of naphthoquinone pigment formation. Similarly, Boonyapranai et al. (2008) [20] investigated that the media added with the mineral salts increased the pigment production than those obtained without the addition of salts. Naphthoquinone production showed high yield in the addition of $\mathrm{K}^{+}, \mathrm{Na}^{+}, \mathrm{Mn}^{+}$, and $\mathrm{Mg}^{+}$while there was a decrease in the pigment production when mineral salt $\mathrm{Zn}^{2+}$ was used in the increased concentration. As there are a number of fungal physiological properties, normally the inoculum age plays an important role in the fungal development $[37,38]$. The results show a maximal pigment production at the fourth day, and similarly, Geweely (2011) [31] reported that the optimal culture condition of the inoculum age was $4 \mathrm{~d}$ for extracellular pigment production by Aspergillus nidulans.

\section{CONCLUSION}

In conclusion, Aspergillus terreus KMBF1501 isolated from the Western Ghats soil produced yellow color pigment was regulated by various factors in the culture medium. Among the six broth medium used, PDB was good for the pigment production. The optimum conditions of different parameters used in work had an effect on the pigment production when Aspergillus terreus KMBF1501 was able to utilize the glucose as a carbon source and peptone as a nitrogen source. There was an immense benefit in adding the $\mathrm{Mg}_{2} \mathrm{So}_{4}$ to the medium and inoculum age in the fourth day to enhance the pigment production, as well as the mycelial growth. Pigment production was favored at the $\mathrm{pH} 5$ and temperature of $27^{\circ} \mathrm{C}$. The highest pigment production by Aspergillus terreus KMBF1501 was achieved when it was cultured in the modified PDB than in the common PDB medium. The high concentration of the pigment produced by Aspergillus terreus KMBF1501 may be used for various industrial purposes.

\section{ACKNOWLEDGEMENT}

The authors are sincerely grateful to the Management, Karpagam University (Karpagam Academy of Higher Education), Coimbatore-641 021, Tamil Nadu, India, for the constant encouragement and support.

\section{CONFLICT OF INTERESTS}

No conflict of interest

\section{REFERENCES}

1. Gupta R, Gigras P, Mohapatra H, Goswamy VK, Chauhan B. Microbial $\alpha$-amylase a biotechnological perspective. Proc Biochem 2003;4:1-18.

2. Kulkarni P, Gupta N. Screening and evaluation of soil fungal isolates for xylanase production. Rec Res Sci Technol 2013;5:33-6.

3. Khaldi N, Seifuddin FT, Turner G, Haft D, Nierman WC, Wolfe $\mathrm{KH}$, et al. SMURF: Genomic mapping of fungal secondary metabolite clusters. Fungal Gen Biol 2010;47:736-41.

4. Tajick MA, Khani HSM, Babaeizad V. Identification of secondary biological metabolites in three Penicillium species, $P$. goditanum, P. moldavicum and P. corylophilum. Prog Biol Sci 2013;4:53-61.

5. Brakhage AA. Regulation of fungal secondary metabolism. Prog Biol Sci 2012;11:21-32.

6. Downham A, Collins P. Colouring our foods in the last and next millennium. Int J Food Sci Technol 2000;35:5-22.

7. Mapari SAS, Nielsen KF, Larsen TO, Frisvad JC, Meyer AS, Thrane U. Exploring fungal biodiversity for the production of water-soluble pigments as a potential natural food colorant. Curr Opin Biotechnol 2005;16:231-8.

8. Chen $\mathrm{MH}$, John MR. Effect of $\mathrm{pH}$ and nitrogen source on pigment production by Monascus purpureus. Appl Microbiol Biotechnol 1993;40:132-8.

9. Caro Y, Anamale L, Fouillaud M, Laurent P, Petit T, Dufosse L. Natural hydroxyanthraquinoid pigments as potent food grade colorants: overview. Nat Prod Bioprospect 2012;2:174-93.

10. Dufosse L, Galaup P, Yaron A, Arad SM, Blanc P, Murthy KNC, et $a l$. Microorganism and microalgae as a source of pigments for food use: a scientific oddity or an industrial reality. Trends Food Sci Technol 2005;16:389-406.

11. Akilandeswari P, Pradeep BV. Exploration of industrially important pigments from soil fungi. Appl Microbiol Biotechnol 2016;100:1631-43.

12. Calvo AM, Wilson RA, Rok JW, Keller NP. Relation between secondary metabolism and fungal development. Microbiol Mol Bol Rev 2002;66:447-59.

13. Gill M. Pigments of fungi (Macrocycetes). Nat Prod Rep 1999;16:301-17.

14. Teixeria MFS, Martins MS, Silva JCD, Kirsch LS, Fernandes OC, Carneirol ALB, et al. Amazion biodiversity: pigments from Aspergillus and Penicillium-characterizations, antibacterial activities and their toxicities. Curr Trends Biotechnol Pharm 2012;6:300-11.

15. Atalla MM, Elkhrisy EAM, Asem MA. Production of textile reddish brown dyes by fungi. Malays J Microbiol 2011;7:33-40. 
16. Khattak SU, Iqbal Z, Lutfullah G, Bacha N, Khan AA, Saeed M, Ali M. Phytotoxic and herbicidal activities of Aspergillus and Penicillium species isolated from rhizosphere and soil. Pak J Weed Sci Res 2014;20:293-303.

17. Gao $\mathrm{H}$, Guo $\mathrm{W}$, Wang $\mathrm{Q}$, Zhang $\mathrm{L}$, Zhu $\mathrm{M}$, Zhu $\mathrm{T}$, et al. Aspulvinones from a mangrove rhizosphere soil-derived fungus Aspergillus terreus Gwq-48 with anti-influenza A viral (H1N1) activity. Bioorg Med Chem Lett 2013;23:1776-78.

18. Kaji A, Saito R, Nomura M, Miyamoto K, Kiriyama N. Mechanism of the cytotoxicity of asterriquinone, a metabolite of Aspergillus terreus. Anticancer Res 1997;17:3675-9.

19. Barnett HL, Hunter BB. Illustrated genera of imperfect fungi. $4^{\text {th }}$ edition USA: Burgess Publishing Co; 1998.

20. Boonyapranai K, Tungpradit R, Hieochaiphant S. Optimization of submerged culture for the production of naphthoquinones pigment by Fusarium verticilloides. Chiang Mai J Sci 2008;35:457-66.

21. Cho YJ, Park JP, Hwang HJ, Kim SW, Choi JW, Yun JW. Production of red pigment by submerged culture of Paecilomyces sinclairii. Lett Appl Microbiol 2002;35:195-202.

22. Olsson L, Nielsen J. Online and in situ monitoring of biomass in submerged cultivations. Tibitechnol; 1997.p. 522.

23. Celestino JdR, Carvalho Led, Lima MdP, Lima AM, Ogusku MM, Souza JVBd. Bioprospecting of Amazon soil fungi with the potential for pigment production. Proc Biochem 2014:49:569-75.

24. Velmurugan $P$, Kamala-Kannan $S$, Balachandar V, Lakshmanaperumalsamy $P$, Chae JC, Taekoha B. Natural pigment extraction from five filamentous fungi for industrial applications and dyeing of leather. Carbohydr Polym 2010;79:262-8

25. Pradeep BV, Stanly Pradeep F, Angayarkanni J, Palaniswamy M. Optimization and production of prodigiosin from Serratia marcescens MBB05 using various natural substrates. Asian J Pharm Clin Res 2013;6:34-41.

26. Berovic M, Koloini T, Olsvik ES, Kristiansen B. Rheological and morphological properties of submerged citric acid fermentation broth in stirred tank and bubble column reactors. Chem Eng J 1991;53:35-40.
27. Goudar CT, Strevett KA, Shah SN. Influence of microbial concentration on the rheology of non-Newtonian fermentation broths. Appl Microbiol Biotechnol 1999;51:310-5.

28. Feng Y, Shao Y, Chen F. Monascus pigments. Appl Microbiol Biotechnol 2012;96:1421-40.

29. Nomila Merlin J, Nimal Christhudas IVS, Praveen Kumar P, Agastian P. Optimization of growth and bioactive metabolite production: Fusarium solani. Asian J Pharm Clin Res 2013;6:98-103

30. Morton AG, Macmillan A. The animitalics of nitrogen from ammonium salts and nitrate by fungi. J Exp Bot 1954;5:232-52.

31. Geweely NS. Investigation of the optimum condition and antimicrobial activities of pigments from four potent pigmentproducing fungal species. J Life Sci 2011;5:697-711.

32. Demain AL. Regulation of secondary metabolism in fungi. Pure Appl Chem 1986;58:219-26.

33. Juzlova P, Martinkova L, Khen V. Secondary metabolites of the fungus Monascus: a review. J Ind Microbiol 1996;16:163-70.

34. Lin TF, Demain AL. Effect of nutrition of Monascus sp. on the formation of red pigments. Appl Microbiol Biotechnol 1991;36:70-5.

35. Weinberg ED. Mineral element control of microbial secondary metabolism. In: Microorganisms and Minerals. ED Weinberg. Ed; 1977. p. 289-316.

36. Mendentsev AG, Akimenko VK. Naphthoquinone metabolites of the fungi. Phytochem 1998;47:935-59.

37. Glazebrook MA, Vining LC, White RL. Growth morphology of Streptomyces akiyo shinensis in submerged culture: influence of $\mathrm{pH}$, inoculum and nutrients. Can J Microbiol 1992;38:98-103.

38. Bae JT, Singa J, Park JP, Song CH, Yun JW. Optimization of submerged culture condition for exopolymer production by Paecilomyces japonica. J Microbiol Biotechnol 2000;10:482-7.

\section{How to cite this article}

- $\quad$ P Akilandeswari, BV Pradeep. Aspergillus terreus KMBF1501 a potential pigment producer under submerged fermentation. Int J Pharm Pharm Sci 2017;9(4):38-43. 